\title{
PENGARUH SERVANT LEADERSHIP DAN KOMUNIKASI ORGANISASI TERHADAP KOMITMEN ORGANISASI
}

\author{
I Made Septiadi ${ }^{1}$ \\ I G A Dewi Adnyani \\ ${ }^{1,2}$ Fakultas Ekonomi dan Bisnis Universitas Udayana, Bali, Indonesia \\ e-mail: madeseptiadi@gmail.com
}

\begin{abstract}
ABSTRAK
Sumber daya manusia merupakan aset paling penting dalam suatu organisasi, karena merupakan sumber yang mengendalikan organisasi serta mempertahankan dan mengembangkan organisasi dalam menghadapi berbagai tuntutan perusahaan. Tujuan dari penelitian ini adalah untuk menguji pengaruh servant leadership dan komunikasi organisasi terhadap komitmen organisasi pada karyawan Livingstone Cafe \& Bakery Seminyak Bali. Dalam penelitian ini digunakan metode sensus (total sampling) dalam menentukan sampel sebanyak 57 responden, melalui teknik analisis regresi linear berganda. Berdasarkan hasil analisis dapat diketahui bahwa servant leadership memiliki pengaruh positif dan signifikan terhadap komitmen organisasi pada karyawan Livingstone Cafe \& Bakery Seminyak Bali. Komunikasi organisasi memiliki pengaruh positif dan signifikan terhadap komitmen organisasi pada karyawan Livingstone Cafe \& Bakery Seminyak Bali.
\end{abstract}

Kata kunci: servant leadership, komunikasi organisasi, komitmen organisasi

\begin{abstract}
Human resources are the most important asset in an organization, because it is the source that controls the organization and maintains and develops the organization in the face of various demands of the company. The purpose of this research is to examine the influence of servant leadership and organizational communication on organizational commitment to Livingstone Cafe \& Bakery Bali Seminyak employees. In this study used the method of census (total sampling) in determining the sample of 57 respondents, through multiple linear regression analysis techniques. Based on the results of the analysis can be seen that servant leadership has a positive and significant influence on organizational commitment to employees Livingstone Cafe \& Bakery Seminyak Bali. Organizational communication has a positive and significant influence on organizational commitment to Livingstone Cafe \& Bakery Bali Seminyak employees.
\end{abstract}

Keywords: servant leadership, organizational communication, organizational commitment 
I Made Septiadi dan I G A Dewi Adnyani, Pengaruh Servant Leadership.....

\section{PENDAHULUAN}

Seiring dengan perkembangan zaman yang kian pesat tanpa kita sadari telah berpengaruh pada pergeseran pola pikir karyawan akan pentingnya komitmen terhadap organisasi sebagai aktivitas dasar di dalam perusahaan. Komitmen terhadap organisasi diyakini dapat menghasilkan pedoman bagi keputusankeputusan dan tindakan-tindakan individu dan mempengaruhi pesan-pesan mengenai organisasi (Mustikadewi, 2015). Komitmen terhadap organisasi berguna untuk memahami dedikasi bawahan terhadap organisasi kerjanya. Ini artinya bahwa seseorang karyawan yang mempunyai komitmen terhadap organisasi, memaknai kerja dengan hal yang luhur mengindikasikan bahwa mereka dekat dengan tujuan organisasi yang akan dicapai. Oleh karena itu, organisasi berkepentingan dengan berkembangnya sumber daya manusia yang memiliki komitmen terhadap organisasi/perusahaan (Fitriani, 2016).

Bisnis/perusahaan jasa sangat berpengaruh dalam dunia modern saat ini, dalam berbagai aktivitas kita sehari-hari seringkali terbantu dan bahkan tergantung pada jasa (Cem and Suat, 2012). Pertumbuhan pada sektor jasa semakin meningkat, beberapa contoh bisnis di bidang jasa antara lain adalah jasa penginapan, café \& bar, restoran, home stay. Tjiptono (2008: 10) menekankan bahwa jasa merupakan sesuatu yang bisa dipertukarkan namun kerapkali sulit dialami atau dirasakan secara fisik. Sejalan dengan itu, Vania dan Roy (2013) menyatakan aktivitas jasa adalah setiap tindakan atau manfaat yang dapat ditawarkan oleh satu pihak kepada pihak lain yang pada esensinya tidak berwujud dan tidak mengakibatkan kepemilikan sesuatu, produksinya dapat atau tidak dapat 
dikaitkan dengan suatu produk fisik. Perusahaan jasa di Provinsi Bali yang mengalami pertumbuhan sangat pesat tentunya di dunia pariwisata seperti restoran yang dirasakan semakin maju sehingga membawa dampak pada persaingan yang semakin kompetitif. Situasi seperti ini menyebabkan pimpinan dan karyawan perusahaan, khususnya restoran dituntut untuk selalu bertindak secara professional dan terorganisir dalam mencapai tujuan perusahaan.

Perusahaan memiliki tugas mendasar yaitu untuk mempengaruhi sikap dan perilaku klien. Perusahaan yang bergerak di bidang jasa harus berorientasi pada pelanggan, yaitu memuaskan para klien. Melalui komunikasi yang efektif maka perusahaan jasa mampu membina hubungan baik yang dinamis dan harmonis dengan klien. Customer relations merupakan salah satu kegiatan yang penting dilakukan oleh perusahaan jasa karena menyangkut masa depan jalannya perusahaan. Dalam upaya peningkatan pemberian pelayanan jasa kepada pelanggan, perusahaan perlu menekankan visinya dalam kegiatan pemenuhan kebutuhan dan keinginan para pelanggannya tersebut melalui komitmen karyawan pada organisasi (Vania dan Roy, 2013).

Komitmen organisasi didefinisikan oleh beberapa peneliti sebagai ukuran dari kekuatan identitas dan keterlibatan karyawan dalam tujuan dan nilai-nilai organisasi. Luthans (2006:112) mendefinisikan komitmen organisasi sebagai sebuah sikap yang merefleksikan loyalitas karyawan kepada organisasi dan merupakan suatu proses berkelanjutan dimana anggota organisasi mengungkapkan perhatian mereka terhadap organisasi, terhadap keberhasilan organisasi serta kemajuan yang berkelanjutan (Wike dan Meily, 2012). Bagi perusahaan jasa, 
pelayanan dihasilkan dan dikonsumsi pada waktu yang sama. Berbeda dengan perusahaan yang menjual barang, jasa pembuatan barang dihasilkan sebelum barang tersebut dikonsumsi. Oleh sebab itu pihak perusahaan dan pelanggan terlibat secara personal dalam transaksi pelayanan (Mustikadewi, 2015). Pengalaman pelayanan ini penting, bila petugas yang melayani pelanggan menunjukkan sikap yang tidak ramah dan wajah yang suram maka pelanggan akan merasa tidak senang dan mungkin saja ia tidak akan kembali lagi ke tempat tersebut, sebaliknya bila petugas itu menunjukkan sikap yang ramah dan menyenangkan maka tamu akan senang dan merasa puas.

Sumber daya manusia merupakan aset paling penting dalam suatu organisasi, karena merupakan sumber yang mengendalikan organisasi serta mempertahankan dan mengembangkan organisasi dalam menghadapi berbagai tuntutan zaman (Fery, 2013). Sumber daya manusia perlu dikembangkan secara terus menerus agar diperoleh sumber daya manusia yang bermutu dalam artian sebenarnya yaitu pekerjaan yang dilaksanakan akan menghasilkan sesuatu yang dikehendaki. Oleh karena itu komitmen organisasi merujuk kepada keberpihakan dan kesetiaan karyawan kepada perusahaan dan tujuan-tujuan perusahaan (Vania, 2013).

Livingstone Cafe \& Bakery Seminyak Bali adalah salah satu café \& bar yang memiliki konsep café \& bar berkonsep gaya Eropa dengan masakan Eropa dengan menyediakan sajian breakfasts and freshly-brewed coffees. Perusahaan ini memiliki visi menjadi café \& bar yang terbaik dan terdepan dalam dunia pariwisata khususnya di Bali dengan moto "is a great place to start your day". 
Sedangkan misinya ingin lebih meningkatkan produktivitas, efesiensi dan efektif dalam bidangnya. Untuk dapat mengantisipasi persaingan, perusahaan hendaknya memberikan pelayanan yang baik yang ditawarkan perusahaan. Dalam penyelesaian pekerjaannya memerlukan ketelitian kerja dari para karyawan, maka haruslah didukung dengan memiliki karyawan yang mempunyai komitmen yang baik dan tingkat disiplin yang tinggi dalam mengerjakan segala tugas-tugasnya sehingga tujuan perusahaan dapat tercapai.

Karyawan yang bekerja pada Livingstone Cafe \& Bakery Seminyak Bali yang berlokasi di Jalan Petitenget No.88X, Kerobokan Kelod, Kuta Utara ini berjumlah sebanyak 57 orang karyawan di luar manajer. Livingstone Cafe \& Bakery memiliki jumlah karyawan yang cukup banyak sehingga mengharuskan perusahaan menjalankan pengelolaan karyawan dengan baik agar tercapainya tingkat pelayanan yang maksimal dengan sikap karyawan memahami komitmen pada perusahaan.

Komitmen organisasi karyawan dapat terlaksana dengan baik, dengan peran keefektifan seorang pemimpin di dalam perusahaan. Keputusan dan kebijakan yang dibuat oleh seorang pemimpin diharapkan tidak saja mempengaruhi keberhasilan organisasi, tetapi juga perilaku semua karyawannya (Fery, 2013). Menurut Wike dan Meily (2012) pemimpin tersebut berfungsi untuk menggerakkan para pengikut (follower) agar mereka mau mengikuti atau menjalankan apa yang diperintahkan dan dikehendaki pemimpin. Untuk menggerakan para pengikut, pastilah pemimpin harus memiliki peran. Pemimpin mempunyai wewenang untuk mengarahkan berbagai kegiatan para anggota atau 
I Made Septiadi dan I G A Dewi Adnyani, Pengaruh Servant Leadership.....

kelompok. Perilaku pimpinan ini sering juga sebagai gaya kepemimpinan (style of leadership). Setiap pemimpin bisa mempunyai gaya kepemimpinan yang berbeda antara satu dengan yang lain, dan tidak mesti suatu gaya kepemimpinan lebih baik atau lebih buruk dari pada gaya kepemimpinan yang lainnya. Dari berbagai macam teori mengenai gaya kepemimpinan, menurut pandangan kontemporer, gaya kepemimpinan yang terbaru saat ini serta banyak diminati oleh para peneliti yaitu mengenai gaya kepemimpinan yang melayani (servant leadership).

Servant leadership merupakan suatu tipe atau model kepemimpinan yang dikembangkan untuk mengatasi krisis kepemimpinan berupa menurunnya kepercayaan follower terhadap keteladanan pemimpinnya (Fery, 2013). Hal ini karena perilaku yang dicerminkan dari seorang servant leaders yaitu cenderung menjadi teladan untuk mempengaruhi orang-orang yang dipimpinnya. Contoh perilaku servant leaders misalnya mendengarkan pendapat dari anak buahnya (altruistic calling), menyembuhkan rasa emosional yang sedang bergejolak pada anak buahnya (emotional healing), bijaksana dalam mengambil keputusan (wisdom), lebih mengutamakan tindakan-tindakan persuasif (persuasive mapping) dari pada otoritas posisional seseorang (organizational stewardship) (Adelia et al., 2015). Selain itu, servant leaders biasanya terjun langsung didalam organisasi untuk bisa membangun dan mendorong karyawannya untuk terus berkembang. Hal ini bisa berupa memberikan pelayanan dan pertolongan apabila karyawan mengalami kesulitan dalam organisasi.

Manager sebagai pimpinan Livingstone Cafe \& Bakery Seminyak Bali diindikasikan belum sepenuhnya menerapkan gaya kepemimpinan servant 
leadership. Hal itu ditunjukkan dengan cara berkomunikasi yang belum ramah dan tidak banyak memberi arahan. Minimnya apresiasi yang diberikan oleh manager kepada karyawan yang melakukan pekerjaan dengan baik. Karyawan belum sepenuhnya mendapatkan kesempatan untuk menyampaikan keluhan dan aspirasinya demi kepentingan perusahaan. Manajer kurang melakukan sosialisasi apabila terdapat perubahan peraturan, maupun perubahan manajemen dalam perusahaan kepada karyawan.

Dalam organisasi yang bergerak di bidang non-profit, servant leaders yang diterapkan oleh manager biasanya cenderung berusaha menerapkan hal-hal yang mampu membuat karyawannya tetap berkomitmen terhadap organisasi sehingga menciptakan suasana kerja yang menyenangkan. Servant leaders yang melayani diharapkan dapat menumbuhkan tanggungjawab karyawan pada pekerjaan (Lora, 2015). Perilaku-perilaku tersebut diharapkan dapat memperkecil perasaan tertekan terhadap tuntutan. Karyawan diharapkan dapat bekerja dengan produktif dan loyal pada perusahaan. Manager pada Livingstone Cafe \& Bakery Seminyak belum seluruhnya memposisikan diri sebagai pemimpin yang melayani karyawan. Ditunjukkan dengan hubungan Manager dan karyawan yang kaku, dan kurang memperhatikan hak karyawan. Manager juga tidak memberikan apresiasi pada prestasi dan tidak objektif dalam memberi penilaian terhadap pekerjaan karyawan (Michelle, 2010). Hal-hal tersebut menimbulkan krisis kepercayaan terhadap pemimpin, dan menjadi penyebab rendahnya perilaku komitmen organisasi karyawan Livingstone Cafe \& Bakery Seminyak. 
I Made Septiadi dan I G A Dewi Adnyani, Pengaruh Servant Leadership.....

Fenomena masalah yang menyangkut perilaku komitmen organisasi karyawan yang rendah pada perusahaan ditunjukkan dengan sikap karyawan yang tidur pada saat jam kerja, meninggalkan tempat kerja tanpa izin, menggunakan ponsel pada saat jam kerja, dan bermain game di komputer pada saat jam kerja. Selain itu, karyawan sering berbincang-bincang tentang hal yang tidak berkaitan dengan pekerjaan pada saat jam kerja. Karyawan juga memiliki rasa kepedulian yang rendah terhadap rekan kerja yang membutuhkan bantuan. Perilaku-perilaku tersebut merupakan tindakan yang tidak mendukung efektivitas dan efesiensi dalam bekerja. Karyawan melakukan hal menyimpang atau melanggar, yang menunjukkan tanggungjawab yang rendah pada pekerjaan. Rendahnya prilaku karyawan dapat disebabkan oleh beberapa faktor, antara lain krisis kepercayaan terhadap pemimpin, kepuasan kerja rendah, beban kerja, rasa bosan pada pekerjaan, dan adanya masalah pribadi (Mustikadewi, 2015).

Observasi dilakukan untuk mengetahui penyebab masalah kepemimpinan dengan pengamatan dan wawancara, diketahui ada indikasi kinerja manajer yang tidak profesional. Tindakan itu adalah pimpinan sering mengambil keputusan sendiri tanpa mempertimbangkan karyawan, seperti kebijakan jam kerja dan perlakuan waktu jam istirahat. Menurut karyawan, pemimpin saat ini memiliki rasa kepercayaan yang minim terhadap karyawan sehingga terkesan meremehkan karyawan. Visi misi perusahaan belum sepenuhnya dijalankan oleh pimpinan terkesan perusahaan menjadi tidak up to date dalam memberikan layanan. Kurangnya rasa saling menghormati antar satu sama lain terlihat pada saat wawancara antara pimpinan dan karyawan. Pimpinan bersikap tidak adil, dimana 
hanya memilih orang terdekat saja yang mendapatkan kepercayaan. Hal-hal ini mengindikasikan terjadinya masalah dari pimpinan di Livingstone Cafe \& Bakery Seminyak Bali.

Salah satu faktor untuk merangsang dalam menerapkan komitmen organisasi karyawan adalah komunikasi organisasi (Abdu, 2014). Robbins (2009:297) mendefinisikan komunikasi organisasi sebagai derajat atau tingkat informasi tentang pekerjaan yang dikirimkan organisasi untuk anggota dan diantara anggota organisasi. Tujuan komunikasi dalam organisasi adalah untuk membentuk saling pengertian (mutual understanding) sehingga terjadi kesetaraan kerangka referensi (frame of references) dan kesamaan pengalaman (field of experience) diantara anggota organisasi. Komunikasi organisasi harus dilihat dari berbagai sisi yaitu pertama komunikasi antara atasan kepada bawahan, kedua antara karyawan yang satu dengan karyawan yang lain, ketiga adalah antara karyawan kepada atasan (Orebiyi, 2011).

Hassan et al. (2010) unsur komunikasi merupakan hal yang sangat penting dalam organisasi agar organisasi dapat berjalan dengan baik. Hambatan yang sering dialami karyawan dalam membina kerjasama dengan pimpinan yang akan berpengaruh terhadap komitmen karyawan terhadap perusahaan. Komunikasi organisasi yang efektif dapat membangun situasi kerja yang nyaman dan membangun hubungan yang baik sehingga mendorong karyawan menjalankan profesinya (Adelia et al., 2015). Efektifitas komunikasi antara karyawan dengan pimpinan perusahaan dan rekan sekerja juga mempengaruhi terwujudnya komitmen organisasi di perusahaan. Karyawan yang menjalin komunikasi secara 
efektif akan terus berjuang mencapai tujuan organisasi dengan komitmen yang tinggi. Karyawan juga diharapkan berperan aktif dalam menyampaikan ide dalam mencapai visi dan misi organisasi. Selain itu, kepedulian pada rekan kerja dan sikap toleran dibutuhkan untuk menciptakan suasana kerja yang nyaman dan kondusif (Lalujan et al., 2016).

Pentingnya komunikasi juga dapat dilihat dari manfaat bagi organisasi meliputi fungsi pengendalian, motivasi, pengungkapan emosional dan penyediaan informasi untuk pengambilan keputusan (Robbins, 2009:312). Studi empiris menemukan bahwa efektivitas komunikasi merupakan antesenden komitmen pegawai pada organisasi, absensi dan turnover, dan produktivitas kerja serta pereduksi ambiguitas (ambiguity) informasi bagi bawahan (Umar, 2007:107).

Melalui hasil wawancara terdapat masalah kurangnya komunikasi manajer/ pimpinan dengan karyawan mengakibatkan sulitnya menyatukan visi pimpinan dengan bawahan. Karyawan juga menyatakan bahwa citra umum pemimpin saat ini tidak dapat menjadi panutan bagi pengikutnya. Minimnya sikap saling terbuka untuk mencari solusi dalam menyelesaikan masalah. Sering terjadinya salah paham antara pemimpin dengan karyawan sehingga terkesan ada hubungan yang tidak harmonis di dalam perusahaan. Hal-hal ini mengindikasikan terjadinya masalah komunikasi organiasi di Livingstone Cafe \& Bakery Seminyak Bali

Beberapa penelitian membuktikan bahwa komunikasi organisasi berpengaruh terhadap komitmen organisasi. Erlan (2013) membuktikan dukungan komunikasi organisasi memiliki pengaruh positif pada komitmen organisasi. Fitriani et al. (2016) menyatakan bahwa komunikasi organisasi memiliki 
pengaruh positif pada komitmen organisasi pada perusahaan. Haider et al. (2015) menyatakan komunikasi organisasi berpengaruh positif dalam penerapan komitmen organisasi. Lora (2015) komunikasi organisasi berperan positif terhadap komitmen organisasi.

Livingstone Cafe \& Bakery Seminyak Bali juga mengalami persaingan yang ketat dengan usaha sejenis. Untuk mengantisipasi hal tersebut pihak manajemen telah mengupayakan peningkatan pelayanan terhadap pelanggan. Untuk dapat memberikan pelayanan yang baik dan memuaskan kepada pelanggan diperlukan adanya sikap komitmen organisasi karyawan.

Penelitian selanjutnya telah membuktikan bahwa servant leadership dapat mempengaruhi komitmen organisasi. Fery et al. (2013) mengatakan bahwa peran servant leadership merupakan salah satu faktor yang dapat memberikan pengaruh positif terhadap komitmen organisasi. Syahfarnas (2014) memberikan pendapat yang sama peran servant leadership memberikan pengaruh positif terhadap komitmen organisasi. Hal ini didukung oleh Asif et al. (2013) servant leadership yang diterapkan oleh seorang pemimpin mampu meningkatkan dan memberikan pengaruh positif terhadap komitmen organisasi. Berdasarkan pemahaman tersebut dapat dirumuskan hipotesis pertama sebagai berikut.

$\mathrm{H}_{1}$ : servant leadership memiliki pengaruh positif terhadap komitmen organisasi

Penelitian selanjutnya telah membuktikan bahwa komunikasi organisasi dapat mempengaruhi komitmen organisasi. Hassan et al. (2010) komunikasi organisasi mempunyai pengaruh positif terhadap komitmen organisasi karyawan dalam menjalankan tugas-tugas yang dibebankan kepadanya. Tiur (2013) 
I Made Septiadi dan I G A Dewi Adnyani, Pengaruh Servant Leadership.....

mengatakan bahwa komunikasi organisasi memiliki keterkaitan positif terhadap komitmen organisasi. komitmen organisasi akan tercipta apabila setiap karyawan memiliki komunikasi organisasi yang efektif (Manoela, 2013). Berdasarkan pemahaman tersebut dapat dirumuskan hipotesis kedua sebagai berikut.

$\mathrm{H}_{2}$ : Komunikasi organisasi memiliki pengaruh positif terhadap komitmen organisasi

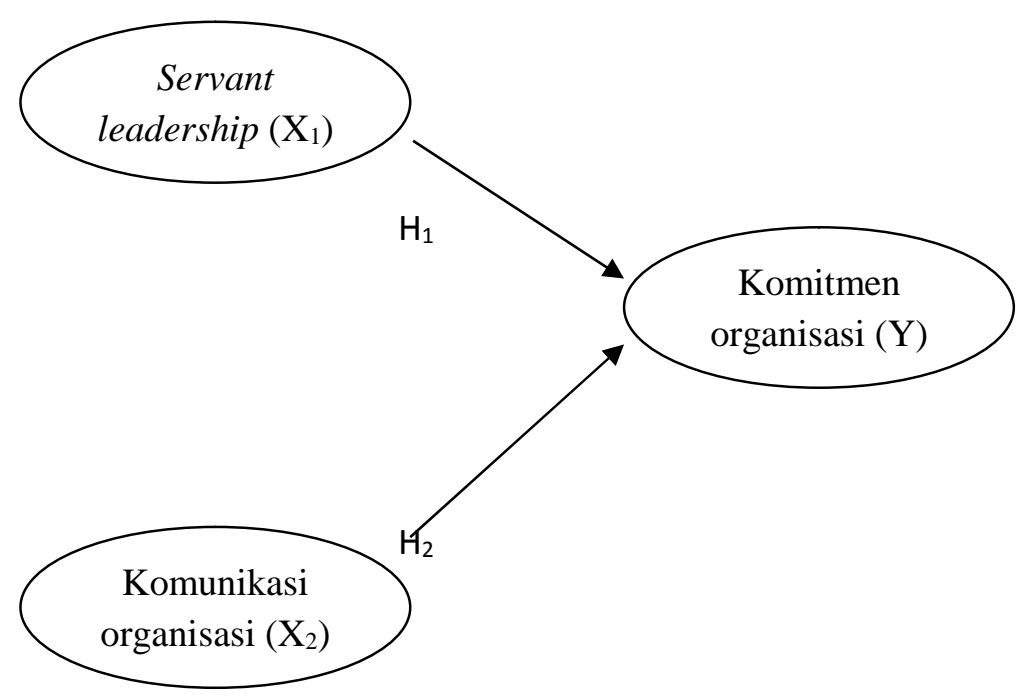

\section{Gambar 1. Desain Penelitian}

Sumber :

$\mathrm{H}_{1} \quad$ : Fery et al. (2013), Syahfarnas (2014), dan Asif et al. (2013)

$\mathrm{H}_{2} \quad$ : Hassan et al. (2010), Tiur (2013), dan (Manoela, 2013)

\section{METODE PENELITIAN}

Penelitian ini menggunakan penelitian asosiatif (hubungan), yaitu penelitian yang bertujuan untuk mengetahui hubungan dari variabel atau lebih (Sugiyono, 2012 :5). Dalam penelitian ini jenis hubungannya adalah hubugan linier karena bertujuan untuk mengetahui variabel-variabel yang mempengaruhi komitmen organisasi. 
Lokasi penelitian dilakukan di Livingstone Café \& Bakery Seminyak Bali adalah, yang beralamat di jalan Petitenget No.88X, Kerobokan Kelod, Kuta Utara, Kabupaten Badung. Adapun alasan yang melatarbelakangi peneliti melakukan penelitian karena usaha yang bergerak dibidang jasa pariwisata, harus mampu memberikan jaminan atas kualitas layanan kepada pelanggan, dan adanya dukungan dari pendapat ahli yang digunakan dalam studi ini dimana komitmen organisasi ialah faktor pendukung perusahaan dalam meningkatkan gairah kerja karyawan dalam mendukung tujuan perusahaan. Sedangkan obyek dalam penelitian adalah bidang perilaku organisasi yaitu pengaruh servant leadership dan komunikasi organisasi terhadap komitmen organisasi.

Variabel terikat dalam penelitian ini adalah komitmen organisasi (Y) yang diukur dengan menggunakan tiga indikator yaitu Komitmen afektif, Komitmen berkelanjutan, dan Komitmen normative. Variabel bebas dalam penelitian ini adalah Servant leadership dan Komunikasi organisasi yang masing-masing diukur dengan menggunakan indicator. Servant leadership (X1) diukur dengan menggunakan lima indikator yaitu Kasih sayang, Pemberdayaan, visi, Kerendahan hati, dan Kepercayaan. Sedangkan Komunikasi organisasi diukur dengan menggunakan lima indikator yaitu Kualitas media, Kemudahan mendapatkan informasi, Penyebaran informasi, Muatan informasi, dan Kemurnian pesan.

Jenis data yang digunakan dalam penelitian ini adalah data kuantitatif, berupa data jumlah karyawan, jawaban responden terhadap kuisioner. Data kualitatif dalam penelitian ini berupa sejarah perusahaan, struktur organisasi dan aktivitas perusahaan. Sedangkan sumber data yang digunakan dalam penelitian ini 
adalah sumber primer yang diperoleh secara langsung dari Livingstone Café \& Bakery Seminyak, diamati dan dicatat untuk pertama kalinya oleh peneliti, data ini didapatkan dengan observasi dan pemberian kuesioner kepada responden yaitu karyawan Livingstone Café \& Bakery Seminyak. Sedangkan sumber sekunder dalam penelitian ini berupa sejarah berdirinya perusahaan dan struktur organisasi perusahaan.

Populasi dalam penelitian ini adalah karyawan Livingstone Café \& Bakery Seminyak sebanyak 57 orang di luar manager mengenai pertanyaan yang memiliki keterkaitan dengan servant leadership, komunikasi organisasi dan komitmen organisasi.

Metode pengumpulan data yang digunakan dalam penelitian ini adalah observasi dengan cara mengadakan pengamatan langsung ke perusahaan terhadap obyek yang diteliti, seperti aktivitas kerja karyawan. Kuisioner dengan menggunakan daftar pertanyaan yang disebarkan kepada responden (karyawan) berkaitan dengan servant leadership dan komunikasi organisasi yang mempengaruhi komitmen organisasi karyawan Livingstone Café \& Bakery Seminyak.

Teknik analisis data yang digunakan dalam penelitian ini adalah teknik analisis regresi linier berganda Model regresi linier berganda dirumuskan sebagai berikut.

$$
\mathrm{Y}=\alpha+\beta_{1} X_{1}+\beta_{2} X_{2}+\mu i
$$

Dimana :

$\mathrm{Y} \quad=$ Komitmen organisasi

$\mathrm{X}_{1} \quad=$ Servant leadership 
$\mathrm{X}_{2}=$ Komunikasi organisasi

$\alpha=$ Konstanta

$\beta_{1-} \beta_{2}=$ Koefisien regresi dari $X_{1}-X_{2}$

$\mu i=$ Variabel pengganggu (residual error) yang mewakili faktor lain berpengaruh terhadap Y namun tidak dimasukkan dalam model.

\section{HASIL DAN PEMBAHASAN}

\section{Karakteristik Responden}

Dari hasil penelitian yang dilakukan terhadap karyawan di Livingstone Café \& Bakery Seminyak, dapat diketahui gambaran tentang karakteristik responden yang meliputi tiga aspek yaitu umur, jenis kelamin, dan pendidikan terakhir.

Tabel 1.

Karakteristik Responden

\begin{tabular}{|c|c|c|c|c|}
\hline No & Variabel & Klasifikasi & $\begin{array}{l}\text { Jumlah } \\
\text { (orang) }\end{array}$ & $\begin{array}{c}\text { Persentase } \\
(\%)\end{array}$ \\
\hline \multirow{5}{*}{1} & \multirow{4}{*}{ Umur } & $16-25$ & 21 & 36,8 \\
\hline & & $26-35$ & 29 & 50,8 \\
\hline & & $36-45$ & 5 & 8,7 \\
\hline & & $46-60$ & 2 & 3,5 \\
\hline & & lah & 57 & 100 \\
\hline \multirow{3}{*}{2} & Jenis & Laki-laki & 34 & 59,6 \\
\hline & Kelamin & Perempuan & 23 & 40,4 \\
\hline & & lah & 57 & 100 \\
\hline \multirow[t]{5}{*}{3} & & SLTP & 3 & 5,2 \\
\hline & Pendidikan & SLTA & 8 & 14,1 \\
\hline & \multirow[t]{2}{*}{ Terakhir } & Diploma III & 29 & 50,8 \\
\hline & & Sarjana (S.1) & 17 & 29,8 \\
\hline & \multicolumn{2}{|c|}{ Jumlah } & 57 & 100 \\
\hline
\end{tabular}

Sumber: Data primer, data diolah, 2018

Berdasarkan Tabel 1. diketahui bahwa responden sebagian besar berumur 26-35 tahun yaitu sekitar 50,8 persen dari total responden. Di sisi lain responden pada kelompok umur 46-60 persentasenya paling rendah yaitu 3,5 persen. Hal ini berarti bahwa, karyawan Livingstone Café \& Bakery Seminyak rata-rata berumur 26-35 tahun di mana Livingstone Café \& Bakery Seminyak bermaksud untuk 
membina tenaga kerja yang energik dengan berpenampilan menarik sehingga dalam memberikan pelayanan kepada konsumen merasa nyaman dan senang.

Berdasarkan jenis kelamin dapat diketahui bahwa sebagian besar responden yaitu 59,6 persen adalah laki-laki dan 40,4 persen adalah perempuan, ini berarti sistem manajemen Livingstone Café \& Bakery Seminyak lebih membutuhkan karyawan laki-laki jika dikaitkan dengan kesesuaian jenis pekerjaan yang tersedia.

Berdasarkan pendidikan terakhir dapat diketahui bahwa sebagian besar responden yaitu 50,8 persen responden berpendidikan Diploma III, 29,8 persen berpendidikan Sarjana (S.1), 14,1 persen berpendidikan SLTA, dan 5,2 persen berpendidikan SLTP, hal tersebut mengindikasikan baiknya kualitas sumber daya manusia yang dimiliki karyawan Livingstone Café \& Bakery Seminyak lebih mengutamakan karyawan yang memiliki keahlian, pengetahuan atau skill sesuai bidangnya.

\section{Hasil Uji Validitas}

Uji validitas bertujuan untuk menguji sejauh mana intrumen yang digunakan dalam penelitian ini mampu mengukur variabel yang telah ditetapkan oleh peneliti. Suatu instrumen yang valid ditunjukkan dengan r Pearson Correlation skor total $\geq 0,30$.

Tabel 2 menunjukkan bahwa masing-masing indikator variabel memiliki nilai person correlation lebih besar dari 0,30, maka ini berarti indikator/pertanyaan yang digunakan layak digunakan untuk mengukur apa yang seharusnya diukur, dan dapat mengungkap data dari variabel yang diteliti secara tepat. 
Tabel 2.

Hasil Uji Validitas

\begin{tabular}{ccccc}
\hline No & Variabel & Indikator & Korelasi & Keterangan \\
\hline \multirow{4}{*}{1} & & $\mathrm{X} 1.1$ & 0,675 & Valid \\
& \multirow{3}{*}{ Servant leadership $\left(\mathrm{X}_{1}\right)$} & $\mathrm{X} 1.2$ & 0,724 & Valid \\
& & $\mathrm{X} 1.3$ & 0,756 & Valid \\
& & $\mathrm{X} 1.4$ & 0,773 & Valid \\
& & $\mathrm{X} 1.5$ & 0,741 & Valid \\
& & $\mathrm{X} 2.1$ & 0,633 & Valid \\
2 & \multirow{3}{*}{ Komunikasi organisasi $\left(\mathrm{X}_{2}\right)$} & $\mathrm{X} 2.2$ & 0,700 & Valid \\
& & $\mathrm{X} 2.3$ & 0,616 & Valid \\
& & $\mathrm{X} 2.4$ & 0,684 & Valid \\
& & $\mathrm{X} 2.5$ & 0,729 & Valid \\
4 & \multirow{3}{*}{ Komitmen Organisasi $(\mathrm{Y})$} & $\mathrm{Y} 1$ & 0,703 & Valid \\
& & $\mathrm{Y} 2$ & 0,832 & Valid \\
& & $\mathrm{Y} 3$ & 0,914 & Valid \\
\hline
\end{tabular}

Sumber : Data primer diolah, 2018

\section{Hasil Uji Reliabilitas}

Uji reliabilitas mampu menunjukan sejauh mana instrument dapat dipercaya dan diharapkan. Nilai suatu instrument dikatakan reliable apabila nilai Alpha Cronbach $\geq 0,6$. Hasil uji reliabilitas dapat dilihat pada Tabel 3 .

Tabel 3.

Hasil Uji Reliabilitas

\begin{tabular}{clcc}
\hline No & \multicolumn{1}{c}{ Variabel } & Cronbach's Alpha & Keterangan \\
\hline 1 & Servant leadership $\left(\mathrm{X}_{1}\right)$ & 0,782 & Reliabel \\
2 & Komunikasi organisasi $\left(\mathrm{X}_{2}\right)$ & 0,697 & Reliabel \\
3 & Komitmen Organisasi $(\mathrm{Y})$ & 0,755 & Reliabel \\
\hline \multicolumn{2}{l}{ Sumber $:$ Data primer diolah, 2018} & &
\end{tabular}

Tabel 3 di atas menunjukkan bahwa nilai Cronbach's Alpha untuk masingmasing variabel $>0,6$, ini berarti alat ukur tersebut akan memberikan hasil yang konsisten apabila alat ukur tesebut digunakan kembali untuk meneliti obyek yang sama. 
I Made Septiadi dan I G A Dewi Adnyani, Pengaruh Servant Leadership.....

\section{Hasil Uji Normalitas}

Uji normalitas menggunakan uji Kolmogorov-Smirnov, dengan uji ini dapat diketahui data yang digunakan berdistribusi normal atau tidak. Apabila Sign t hitung $>0.05$, maka data tersebut berdistribusi normal dan begitu juga sebaliknya (Santoso, 2001).

Tabel 4.

Hasil Uji Kolmogorov-Smirnov

\begin{tabular}{llr}
\hline & & $\begin{array}{c}\text { Unstandardized } \\
\text { Residual }\end{array}$ \\
\hline $\mathrm{N}$ & & 57 \\
Normal Parameters(a,b) & Mean & 0.0000000 \\
& Std, Deviation & 1.13655216 \\
Most Extreme Differences & Absolute & .098 \\
& Positive & .058 \\
Kolmogorov-Smirnov Z & Negative & -.098 \\
Asymp. Sig. (2-tailed) & & .743 \\
Sumber $:$ Data primer diolah, 2018 & & .639 \\
\hline
\end{tabular}

Berdasarkan Tabel 4. hasil yang didapatkan dengan menggunakan uji Kolmogorov-Smirnov dengan signifikansi lebih besar dari 0,05 yaitu 0,639 maka dapat disimpulkan bahwa model regresi terdistribusi secara normal.

\section{Hasil Uji Multikolinieritas}

Uji multikolinieritas digunakan untuk mengetahui apakah antara variabel bebas terjadi multikolinieritas atau tidak. Uji yang digunakan yaitu dengan melihat nilai VIF (Varian Inflation Factor) dan Tolerance pada proses regresi biasa, jika keduanya mendekati 1 atau besaran VIF kurang dari 10 maka model tidak terkena multikolinieritas. Berdasasrkan hasil pengujian multikolinearitas dapat diperoleh hasil sebagai berikut. 
Tabel 5.

Hasil Uji Multikolinearitas

\begin{tabular}{clccc}
\hline & & \multirow{2}{*}{ Model } & \multicolumn{2}{c}{ Collinearity Statistic } \\
No & & Tolerance & VIF \\
\hline 1 & Servant leadership & 0.510 & 1.961 \\
2 & Komunikasi organisasi & 0.510 & 1.961 \\
\hline \multicolumn{2}{l}{ Sumber $:$ Data primer diolah, 2018 }
\end{tabular}

Tabel 5. di atas menunjukkan nilai VIF (Varian Inflatation Factor) tidak lebih dari 10 dan mempunyai angka tolerance tidak kurang dari 0,1 , maka ini berarti dalam model regresi tidak terjadi multikolinearitas.

\section{Hasil Uji Heteroskedasitas}

Uji Heteroskedastisitas bertujuan untuk menguji apakah dalam model terjadi ketidaksamaan varian atau residual satu pengamatan ke pengamatan lainnya. Jika tingkat signifikan lebih besar dari 0,05 maka terjadi heteroskedastisitas.

Tabel 6.

Hasil Uji Heteroskedastisitas

\begin{tabular}{|c|c|c|c|c|c|c|}
\hline \multirow[b]{2}{*}{ Model } & & \multicolumn{2}{|c|}{$\begin{array}{l}\text { Unstandardized } \\
\text { Coefficients }\end{array}$} & \multirow{2}{*}{$\begin{array}{c}\text { Standardized } \\
\text { Coefficients } \\
\text { Beta }\end{array}$} & \multirow{2}{*}{$\mathbf{t}$} & \multirow{2}{*}{ Sig. } \\
\hline & & & $\begin{array}{l}\text { Std. } \\
\text { Error }\end{array}$ & & & \\
\hline 1 & (Constant) & .027 & .632 & & .043 & .966 \\
\hline 2 & Servant leadership & -.012 & .041 & -.055 & -.294 & .770 \\
\hline 3 & Komunikasi organisasi & .056 & .044 & .238 & 1.274 & .208 \\
\hline
\end{tabular}

Berdasarkan Tabel 6. diatas dapat dilihat bahwa hampir semua variabel memiliki nilai sig > 0,05 ini berarti pada model regresi tidak terjadi gejala heteroskedasitisitas. 


\section{Hasil Analisis Regresi Linear Berganda}

Sesuai dengan hasil perhitungan dengan menggunakan program SPSS for windows maka diperoleh hasil analisis regresi linear berganda.

Tabel 7.

Hasil Analisis Regresi Linear Berganda

\begin{tabular}{|c|c|c|c|c|c|}
\hline \multirow{2}{*}{ Variabel } & & \multicolumn{2}{|c|}{ Koefisien Regresi } & \multirow[b]{2}{*}{$\mathbf{t}$} & \multirow{2}{*}{ Sig } \\
\hline & & B & Std. error & & \\
\hline (constant) & & -0.252 & 1.025 & & \\
\hline Servant leadership & & 0.303 & .066 & 4.615 & .000 \\
\hline Komunikasi organisasi & & 0.310 & .072 & 4.320 & .000 \\
\hline Dependen variabel & $:$ & komitmen organisasi & & & \\
\hline F Statistik & : & 66.561 & & & \\
\hline Sig F & : & 0.000 & & & \\
\hline $\mathrm{R}^{2}$ & $:$ & 0.771 & & & \\
\hline
\end{tabular}

Berdasarkan Tabel 7. dapat ditulis persamaan regresi linear berganda sebagai berikut.

$$
Y=-0,252+0,303 X_{1}-0,310 X_{2}
$$

Dimana :

$\mathrm{Y}=$ komitmen organisasi

$\mathrm{X}_{1}=$ servant leadership

$\mathrm{X}_{2}=$ komunikasi organisasi

$\mathrm{R}^{2}=$ koefisien determinasi

Berdasarkan persamaan hasil regresi linear berganda melalui uji SPSS, dapat dijelaskan hal-hal sebagai berikut yaitu nilai konstanta sebesar -0,252 menunjukan bahwa bila servant leadership $\left(\mathrm{X}_{1}\right)$, komunikasi organisasi $\left(\mathrm{X}_{2}\right)$ sama dengan nol, maka nilai komitmen organisasi (Y) konstant sebesar $-0,252$ satuan. Nilai koefisien $\beta_{1}=0,303$ berarti menunjukkan bila servant leadership $\left(\mathrm{X}_{1}\right)$ meningkat,bila komunikasi organisasi tepat maka nilai dari komitmen organisasi (Y) akan mengalami peningkatan sebesar 0,303 satuan dengan asumsi variabel 
bebas lainnya konstan. Nilai koefisien $\beta_{2}=0,310$ berarti menunjukkan bila komunikasi organisasi $\left(\mathrm{X}_{2}\right)$ bertambah 1 satuan, maka nilai dari komitmen organisasi (Y) akan mengalami kenaikan sebesar 0,310 satuan dengan asumsi variabel bebas lainnya konstan.

\section{Hasil Uji Koefisien Determinasi}

Berdasarkan Tabel 6. dapat diketahui nilai Adjusted R Square sebesar 0,771 atau 77,1 persen. Berdasarkan nilai toleransi yang diberikan yaitu $\alpha=5$ persen dengan nilai signifikansi $0,000<\alpha(0,05)$ maka $\mathrm{H}_{\mathrm{o}}$ ditolak dan $\mathrm{H}_{\mathrm{i}}$ diterima. Nilai determinasi total sebesar 0,771 mempunyai arti bahwa servant leadership (X1) dan komunikasi organisasi (X2) berpengaruh sebesar 0,771 atau 77,1 persen terhadap komitmen organisasi sedangkan sisanya sebesar 22,9 persen dipengaruhi oleh lain yang tidak masuk dalam model.

\section{Hasil Uji Kelayakan Model (Uji F)}

Sig. Tabel ANOVA menunjukkan besarnya angka probabilitas atau signifikansi pada perhitungan ANOVA. Nilai yang tertera digunakan untuk uji kelayanan Model Analisis (dimana sejumlah $\mathrm{x}$ mempengaruhi y) dengan ketentuan angka probabilitas yang baik untuk digunakan sebagai model regresi harus $<0,05$. Nilai ini bisa dilihat pada kolom Sig. Jika Sig. $<0,05$, maka model analisis dianggap layak. Jika Sig. > 0,05, maka model analisis dianggap tidak layak.

Berdasarkan hasil perhitungan regresi linear berganda yang dirangkum pada

Tabel 7. dapat diketahui bahwa $F_{\text {hitung }}=66,561$ dan nilai $F_{\text {tabel }}$ dengan tingkat 
keyakinan $95 \%$ dan $\alpha=0,05$; df $=(\mathrm{k}-1):(\mathrm{n}-\mathrm{k})=(2: 54)$ adalah sebesar 3,15. Berdasarkan hasil olahan data dapat disimpulkan bahwa servant leadership dan komunikasi organisasi berpengaruh signifikan secara simultan terhadap komitmen organisasi. Hal ini berarti variabel servant leadership dan komunikasi organisasi berpengaruh positif dan signifikan secara simultan terhadap komitmen organisasi karyawan di Livingstone Cafe \& Bakery Seminyak Bali.

\section{Hasil Uji t}

Nilai $\mathrm{t}$ sig untuk servant leadership $<0,05$ maka $\mathrm{H}_{0}$ ditolak artinya servant leadership berpengaruh positif terhadap komitmen organisasi karyawan Livingstone Cafe \& Bakery Seminyak Bali. Positif, erat, dan signifikan dalam arti kedua variabel antara servant leadership dengan komitmen organisasi karyawan saling berpengaruh besar/erat satu sama lain dengan didasarkan pada perhitungan olah data statistik yang signifikan. Hal ini menunjukkan bahwa semakin baik servant leadership yang dirasakan karyawan, maka ada kecenderungan mampu meningkatkan komitmen organisasi.

Nilai $\mathrm{t}$ sig untuk komunikasi organisasi $<0,05$ maka $\mathrm{H}_{0}$ ditolak artinya komunikasi organisasi berpengaruh positif terhadap komitmen organisasi karyawan Livingstone Cafe \& Bakery Seminyak Bali. Tidak positif, erat, dan signifikan dalam arti kedua variabel antara komunikasi organisasi dengan komitmen organisasi karyawan saling berpengaruh besar/erat satu sama lain dengan didasarkan pada perhitungan olah data statistik yang signifikan. Hal ini menunjukkan bahwa semakin baik komunikasi organisasi yang dirasakan karyawan, maka ada kecenderungan meningkatkan komitmen organisasi. 


\section{Pengaruh servant leadership terhadap komitmen organisasi}

Berdasarkan hasil pada Tabel 7 Servant leadership memiliki nilai Beta sebesar 0,303 dan nilai Sig. sebesar 0,000, maka dapat dikatakan $\mathrm{H}_{1}$ diterima karena nilai Sig. $0.000<0,05$. Kesimpulannya adalah bahwa Servant leadership memiliki pengaruh positif dan signifikan terhadap komitmen organisasi, dengan kata lain apabila Servant leadership meningkat maka komitmen organisasi akan semakin meningkat pula.

Hasil analisis data menunjukkan servant leadership memberikan pengaruh positif terhadap komitmen organisasi karyawan pada Livingstone Cafe \& Bakery Seminyak Bali, Robbins (2011:105) mengungkapkan bahwa semakin baik penerapan servant leadership di dalam perusahaan diyakini dapat meningkatkan komitmen organisasi karyawan. Sebaliknya, apabila servant leadership dalam perusahaan tersebut tidak berpihak kepada karyawan, maka akan menurunkan komitmen organisasi karyawan sehingga kinerja perusahaan menjadi menurun secara keseluruhan.

Beberapa penelitian membuktikan yaitu penelitian Fery et al. (2013) mengatakan bahwa peran servant leadership merupakan salah satu faktor yang dapat memberikan pengaruh positif terhadap komitmen organisasi. Syahfarnas (2014) memberikan pendapat yang sama peran servant leadership memberikan pengaruh positif terhadap komitmen organisasi. Hal ini didukung oleh Asif et al. (2013) servant leadership yang diterapkan oleh seorang pemimpin mampu meningkatkan dan memberikan pengaruh positif terhadap komitmen organisasi. 


\section{Pengaruh komunikasi organisasi terhadap komitmen organisasi}

Berdasarkan hasil pada Tabel 7. komunikasi organisasi memiliki nilai Beta sebesar 0,310 dan nilai Sig. sebesar 0,000, maka dapat dikatakan $\mathrm{H}_{2}$ diterima karena nilai Sig. $0.000<0,05$. Kesimpulannya adalah bahwa komunikasi organisasi memiliki pengaruh positif dan signifikan terhadap komitmen organisasi, dengan kata lain apabila komunikasi organisasi meningkat maka komitmen organisasi akan semakin meningkat pula.

Hasil analisis data menunjukkan komunikasi organisasi memberikan pengaruh positif terhadap komitmen organisasi karyawan pada Livingstone Cafe \& Bakery Seminyak Bali, Robbins and Judge (2008: 98) menegaskan komunikasi organisasi merupakan alat yang dilakukan perusahaan sebagai rangsangan dalam meningkatkan komitmen organisasi. Semakin baiknya pelaksanaan komunikasi organisasi diperusahaan akan mampu meningkatkan komitmen organisasi karyawan.

Beberapa penelitian membuktikan yaitu penelitian Hassan et al. (2010) komunikasi organisasi mempunyai pengaruh positif terhadap komitmen organisasi karyawan dalam menjalankan tugas-tugas yang dibebankan kepadanya. Tiur (2013) mengatakan bahwa komunikasi organisasi memiliki keterkaitan positif terhadap komitmen organisasi. komitmen organisasi akan tercipta apabila setiap karyawan memiliki komunikasi organisasi yang efektif (Manoela, 2013).

\section{SIMPULAN}

Berdasarkan pembahasan hasil penelitian di atas, dapat disimpulkan bahwa Servant leadership berpengaruh positif dan signifikan terhadap komitmen 
organisasi karyawan pada Livingstone Cafe \& Bakery Seminyak Bali. Komunikasi organisasi berpengaruh positif dan signifikan terhadap komitmen organisasi karyawan pada Livingstone Cafe \& Bakery Seminyak Bali. Sedangkan saran yang dapat diberikan adalah Manajemen Livingstone Cafe \& Bakery Seminyak Bali dalam menghadapi masalah yang dihadapi karyawan saat ini mengenai penerapan servant leadership diperusahaan pimpinan belum sepenuhnya mampu memilih orang-orang berdasarkan suatu kelebihan sehingga mendapatkan kepercayaan, hal yang harus dilakukan pimpinan sedapat mungkin melakukan penilaian terlebih dahulu kepada karyawan untuk menentukan dalam memberikan pendidikan dan pelatihan sehingga mengetahui keahlian dan kelebihan setiap karyawan untuk ditempatkan dan memberikan kepercayaan demi terwujudnya komitmen organisasi diperusahaan. Manajemen Livingstone Cafe \& Bakery Seminyak Bali dalam menghadapi masalah karyawan saat ini mengenai pelaksanaan komunikasi diperusahaan minimnya komunikasi antara atasan ataupun sesama rekan kerja, hal ini harus menjadi perhatian khusus bagi pihak manajemen dengan mengadakan pertemuan-pertemuan rutin baik secara formal maupun informal dalam bekerja sehingga tercipta komunikasi organisasi secara lisan antara atasan ataupun sesama rekan kerja untuk mewujudkan komitmen organisasi di dalam perusahaan. Manajemen Livingstone Cafe \& Bakery Seminyak Bali dalam menghadapi masalah yang dihadapi karyawan saat ini mengenai komitmen organisasi diperusahaan menyangkut dengan keuntungankeuntungan financial dan ketakutan karyawan yang merasa tidak mendapat 
pekerjaan ditempat lain. Hal ini menjadi perhatian pihak manajemen untuk selalu melibatkan karyawan pada semua kegiatan atau acara yang dilaksanakan.

\section{REFERENSI}

Abdu Ja'afaru Bambale, (2014). Relationship between Servant Leadership and Organizational Citizenship Behaviors: Review of Literature and Future Research Directions. Journal of Marketing and Management. 5 (1): h: 116

Adelia Maris, Wiji Utami, Dewi Prihatini, (2015). Pengaruh Servant Leadership dan Kepribadian terhadap Organizational Citizenship Behavior dalam Meningkatkan Kinerja Guru di Sekolah Dasar Al-Baitul Amien (Full Day School) Jember. Artikel Ilmiah Mahasiswa. pp: 1-7

Asif Shahzad, Riffat Abbas Rizvi, Aamer Waheed, Aamer Waheed, Imran Khan, Sardar M. Usman, Nabila Nazir, Ghazala Amin and Talat Mahmood Kiyani, (2013). Linking Servant Leadership with Organizational Citizenship Behavior through Trust: An Embryonic Structural Modelling Approach. European Journal of Social Sciences. 39(2): h: 273-284

Baron, R.M. and Kenny, D.A. (1986). The moderator-mediator variable distinction in social psychological research: Conceptual, strategic, and statistical considerations. Journal of Personality and Social Psychology. 51(6): 1173-1182

Bright Mahembe and Amos S. Engelbrecht, (2014). The relationship between servant leadership, organisational citizenship behaviour and team effectiveness. SA Journal of Industrial Psychology, 40(1): h: 1-10

Cem Gucel and Suat Begec, (2012). The Effect of the servant leadership on Organizational Citizenship Behavior: Case Study of A University. International Journal Of Social Sciences and Humanity Study. 4(1): h: 107-116

Erlan Bakiev, (2013). The Influence of Interpersonal Trust and Organizational Commitment on Perceived Organizational Performance. Journal of Applied Economics and Business Researce. 3(3): h: 166-180

Fery Handi Putra, (2013). Analisis Pengaruh Komunikasi Interpersonal, Lingkungan kerja fisik dan disiplin kerja terhadap kinerja pegawai perpustakaan IAIN Iman Bonjol Padang. Artikel Tesis Manajemen Universitas Bung Hatta. pp: 1-13 
Fitriani Puspa Ningsih, Rakhmat, Tuti Bahfiarti, (2016). Pengaruh Efektivitas Komunikasi Interpersonal Terhadap Promosi Jabatana pada Dinas Social Daerah Provinsi Sulawesi Tengah. Tesis Ilmu Sosial dan Ilmu Politik Universitas Hasanuddin. pp:1-15

Haider Raza Abid, Amir Gulzar, and Waqar Hussain, (2015). The impact of servant leadership on organizational citizenship behaviors with the mediating role of trust and moderating role of group cohesivenessA Study of public Sector of Pakistan. International Journal of Academic Research in Business and Social Sciences. 5(3): h:234-242

Hassan Zarei Matin, Golamreza Jandaghi, Fateme Haj Karimi, and Ali Hamidizadeh, (2010). Relationship between Interpersonal Communication Skills and Organizational Commitment (Case Study: Jahad Keshavarzi and University of Qom, Iran). European Journal of Social Sciences. 13(3): h: 387-398

Kurnia Atdi Anto, (2015). The Mediating Role of organizational Commitment In Influence Relationships Between Interpersonal Communication and Emotional Intelligence Toward Employee Performance. International Journal of Business, Economics and Law. 7(2): h: 47-56

Kurt T. Dirks, (2009). The Effects of Interpersonal Trust on Work Group Performance. Journal of Applied Psychology. 84: h: 445-455

Lalujan Paramita, Victor P.K. Lengkong, dan Greis M. Sendow, (2016). Pengaruh Komunikasi Organisasi dan Stress Kerja Terhadap Kepuasan Kerja Serta Dampaknya Terhadap Kinerja Karyawan di Perusahaan Umum Bulog Divisi Regional Sulawesi Utara. Jurnal Emba. 4(1): h: 131-142

Lora Reed, (2015). Servant Leadership, Followership, and Organizational Citizenship Behaviors in 9-1-1 Emergency Communications Centers:Implications of a National Study. International Journal of Servant Leadership: Theory and Practice. 2(1): h: 71-94

Manoela Popescu, (2013). Interpersonal Communication Relevance to Professional Development, in Social Systems. International Journal of Academic Research in Business and Social Sciences. 3(4): h: 370-375

Meily Margaretha dan Yanuar Aditia Prasetio, (2012). Pengaruh Servant Leadership, Organizational Citizenship Behavior, Kecocokan OrangOrganisasi Serta Identifikasi Organisasi (Studi Pada Organisasi Kemahasiswaan di Lingkungan Kristen Maranatha). Jurnal Manajemen. 12(1): h: 45-62. 
Michelle Vondey, (2010). The Relationships among Servant Leadership, Organizational Citizenship Behavior, Person-Organization Fit, and Organizational Identification. International Journal of Leadership Studies. 6(1): h: $1-25$

Mustikadewi Kartikarini, (2015). Pengaruh Servant Leadership dan kepuasan kerja terhadap Organizational Citizenship Behaviour (OCB) Karyawan Hotel Bintang-2 di Yogyakarta. Skripsi Manajemen Universitas Negeri Yogyakarta. pp:1-144

Orebiyi, A. O., (2011). the influence of Interpersonal Communication on Secondary School Teachers' Job Satisfaction and three types of Commitments in Kogi State, Nigeria. Journal of Communication and Culture: International Perspective. 2(1): h:109-117

Redi Setiawan, I Gede dan Sudharma, Nyoman, (2015). Pengaruh Kepemimpinan Terhadap Komitmen Organisasi Dimediasi oleh Komunikasi Organisasi Pada PT. Bank Antar Daerah. Jurnal Manajemen Unud. 4(12): h: 40194046.

Robbins, Stephen P., (2009). Perilaku Organisasi, Jilid I, PT.Prenhallindo, Alih Bahasa: Hadyana Pujaatmaka, Jakarta

Robbins, S.P., and Judge, T.A. (2008). Perilaku Organisasi, Edisi Kedua belas,Jakarta: Salemba Empat

Sugiyono. (2012). Metode Penelitian Kuantitatif Kualitatif dan R\&D. Bandung: Alfabeta.

Tiur Asi Siburian, (2013). The Effect of Interpersonal Communication, Organizational Culture, Job Satisfaction, and Achievement Motivation to Organizational Commitment of State High School Teacher in the District Humbang Hasundutan, North Sumatera, Indonesia. International Journal of Humanities and Social Science. 3(12): h: 247-264

Tjiptono, Fandy, (2008). Strategi Pemasaran. Edisi Ketiga. Penerbit ANDI. Yogyakarta. Zikmun, Babin, 2011. Riset Pemasaran. Edisi Sepuluh

Umar Husein, (2007). Riset Sumber Daya Manusia Dalam Organisasi. Edisi Revisi. Jakarta: PT. Gramedia Pustaka Utama.

Vania Claresta km, Prabowo dan Roy Setiawan, (2013). Pengaruh servant leadership dan komitmen organisasional karyawan terhadap organizational citizenship behavior pada Blue Bird Group Surabaya. Jurnal Agora. 1(3): h: 1-12 
E-Jurnal Manajemen Unud, Vol. 8, No. 3, 2019: 1401 - 1429

Wike Santa Mira dan Meily Margaretha, (2012). Pengaruh servant leadership terhadap komitmen organisasional dan Organizational Citizenship Behavior. Jurnal Agora. 11(2): h: 99-116 